\title{
Clinical Hepatocyte Transplantation
}

\author{
Toshio Miki* \\ Department of Surgery, University of Southern California, USA
}

Submission: March 29, 2018; Published: May 21, 2018

"Corresponding author: Toshio Miki, Department of Surgery, Keck School of Medicine, University of Southern California 2011 Zonal Avenue, HMR 509A, Los Angeles, CA 90033-9141, USA, Tel: 323-442-7703; Email: toshiomi@usc.edu

\begin{abstract}
A severe shortage of suitable allograft is a long-standing and worldwide problem for the patients who are waiting for organ transplantation. Hepatocyte transplantation has been proposed as an alternative therapeutic approach for liver disease patients to address these urgent and unmet medical needs. The cell replacement approach does not replace the orthotopic liver transplantation (OLT), but rather complement OLT especially for the patients who are not required whole liver replacement such as congenital metabolic disorders. This review article summarizes current knowledge and limitations of clinical hepatocyte transplantation and aims to advance our understanding towards the goal of developing novel cell replacement therapies for the patients who are on the OLT waiting list.
\end{abstract}

Keywords: Hepatocytes; Congenital metabolic disorders; Cell replacement therapy; Regenerative medicine

\section{Introduction}

Hepatocyte transplantation has been proposed as an alternative approach of the orthotropic liver transplantation (OLT). A number of advantages of this cell replacement therapy over the OLT are listed including less invasiveness and costeffectiveness [1]. The concept of partially replacing damaged or malfunctioned hepatocytes is particularly suitable for the patients who suffer from congenital metabolic disorders and acute liver failure patients who require transient support of their liver function. The keys to the successful hepatocyte transplantation are the indications and the careful evaluation of the eligible recipients, the preconditioning of the recipient's liver, and the quality of the donor cells. The cell transplantation procedure is technically simple compared to that of OLT. The common interventional technique is required to safely deliver the cells to the liver. Here, we briefly overview the reported clinical cases, suitable target diseases, clinical procedures, limitations, and perspective to overcome the limitations.

\section{History}

The basic studies that led to clinical hepatocyte transplantation were initiated in 1970's. Rodent models with metabolic disorders and acute liver failure models induced by chemicals, partial hepatectomy, or ischemic-reperfusion liver injury were often used to demonstrate improvements of damaged liver functions by injecting autologous liver cells [2].
These pre-clinical studies indicated that the allergenic liver cell transplantation had a potential to correct various metabolic defects. The earliest published reports of pre- clinical hepatocyte transplantations were performed in 1976 by a group led by Najarian using UDP-glucuronyl-transferase-deficient rats, the Gunn rat [3]. About a decade later, Mito tested an idea to utilize the spleen as an ectopic liver by transplanting hepatocytes into the spleen with rodent and dog models [4].

The first attempted human hepatocyte transplantation was performed in 1992 by the same group in Japan [5]. The safety of hepatocyte splenic arterial infusion and the therapeutic efficiency were confirmed by Strom [6] with chronic end- stage liver disease patients. They demonstrated that transplanted human hepatocytes were viable in splenic nidation and showed typical hepatic cord structures. Three of five treated patients fully recovered and successfully received OLT. Since then, more than 100 clinical hepatocyte transplantations were reported [7-9]. Over the last two decades, more than 15 institutes around world sporadically conducted clinical hepatocyte transplantation, and currently, at least 7 groups are active [6]. However, despite these successes of the clinical studies, hepatocyte transplantation has remained experimental due to the limited supply of donor liver tissue for hepatocyte isolation. Conducting a large-scale randomized clinical trial has been prohibited by the limited supply of sufficient and consistent quality of human hepatocytes. 


\section{Indications}

Orthotropic liver transplantation (OLT) is a significantly efficient treatment to improve the prognosis in patients with fulminant hepatic failure, end-stage liver disease, and metabolic liver diseases. In theory, if we can replace $100 \%$ of damaged patient's hepatocytes, hepatocyte transplantation can provide similar therapeutic efficacy in most of these diseases. Therefore, the indication of hepatocyte transplantation depends on how much replacement is required to alleviate disease symptoms and how much donor cells can functionally engraft in the patient's liver. In addition, the indications will depend on the risk-benefit balance. Based on this logic, the disease conditions that inhibit donor hepatocyte engraftments such as cirrhotic liver and acute hepatitis will not be suitable.

On the other hand, congenital metabolic disorders (CMDs) will benefit from hepatocyte transplantation. In general, metabolic disease patients require only partial replacement of hepatocytes to compensate for the missing enzyme function. The required compensation level may vary by case and by disease. Careful assessments of the impaired enzyme functions will be required to determine the indication of hepatocyte transplantation. Approximately 1 in 1,500 children is born with a CMD. Many of these critical inborn errors of metabolic or synthetic processes involve principally the liver. Current therapy for CMDs consists of life -long dietary restriction with or without supplementation of amino acids. For example, an infusion of normal hepatocytes that is equivalent to $5 \%$ of the parenchymal mass achieved a medium-term reduction in serum bilirubin in a patient with Crigler-Najjar syndrome [10]. An ornithine transcarbamylase deficient child who received 1.9x109 hepatocytes had normalization of plasma ammonia and glutamine levels on a normal diet without phenylbutyrate/ phenylacetate therapy. These cases clearly demonstrate CMDs can be effectively treated via cell replacement therapy.

Acute liver failures will also benefit from the cell replacement strategy. Although the liver is still in the active inflammation status, injecting hepatocytes into the spleen may support the patients' hepatic function temporarily until the own liver recovers or until the OLT become available. A total of 68 reported clinical hepatocyte transplantation cases can be categorized in these two groups, CMD and ALF (Figure 1). Due to the epidemiologic nature, the patients' ages are significantly distinguished (Figure 2). In most of CMD cases except a case with Progressive familial intrahepatic cholestasis type 2, the therapeutic efficacies were partial but satisfactory. Recipients with some conditions may preclude a successful transplant. Such contraindications may include metastatic cancer outside of the liver, active drug or alcohol abuse, and active systemic infections. However, unlike OLT which is a major surgery with a high incidence of complications, the list of contraindications is shorter for hepatocyte transplantation.

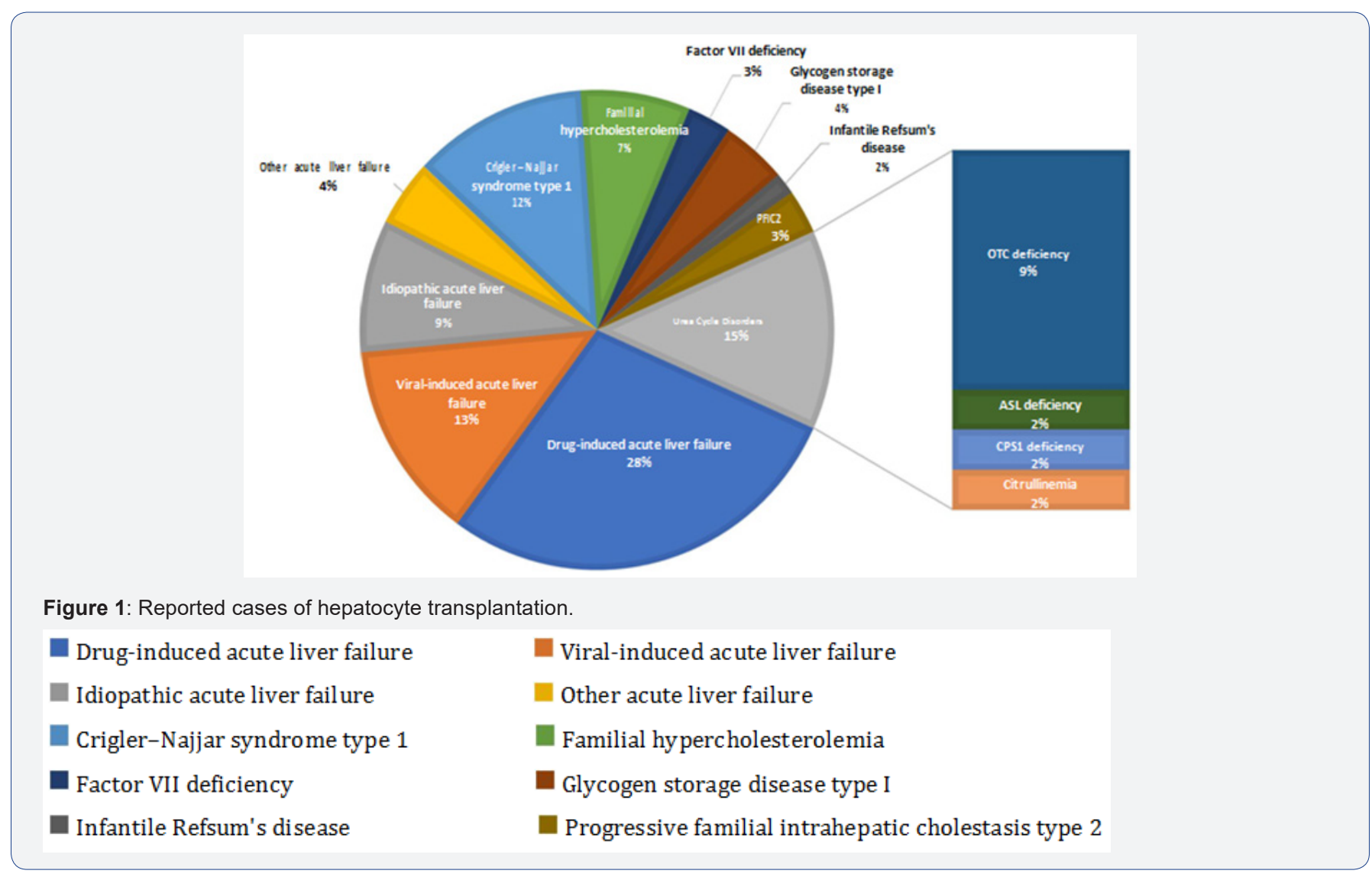




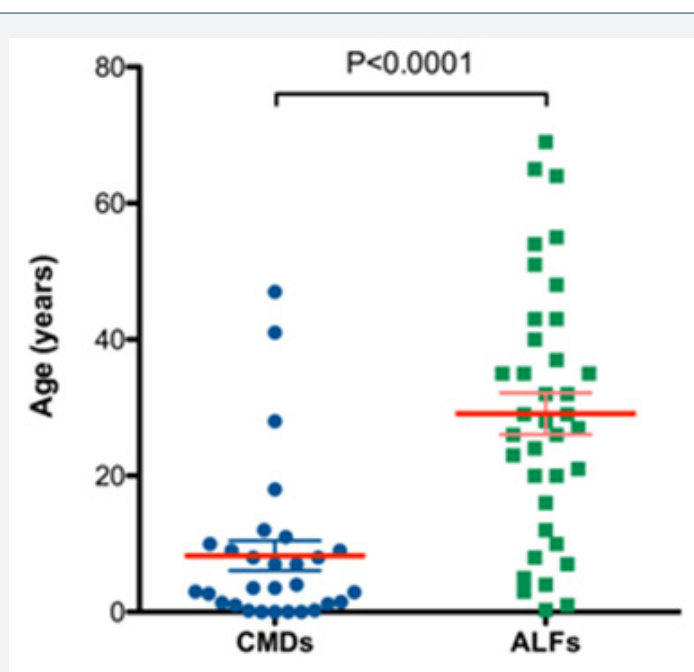

Figure 2

\section{Overview of Clinical Practices}

\section{Cell sources}

The source of primary human hepatocyte is the livers unused for OLT. In result of increasing usage of marginal-suboptimal donor organs with the extended donor criteria (EDC), the availability of organs for cell isolation has diminished. The quality of available donor organ for cell isolation is frequently poor. The degree of steatosis affects the yield, viability, and function [11]. Hepatocytes can be obtained from livers removed from OLT recipients with congenital metabolic disorders. These hepatocytes can be used to treat different types of congenital metabolic disorders [12]. The donor criteria can be extended to advanced-age donors and non-heart-beating donors [13]. However, the cell quality is highly variable. Therefore, these cell sources are not reliable and insufficient to overcome the primary human hepatocyte shortage problem. Hepatocyte Isolation requires well established a unique enzymatic digestion technique. The standard protocol was established based on Seglen's two-step collagenase perfusion technique for rat hepatocytes isolation. The protocol was slightly modified for human hepatocyte isolation [14-16]. Hepatocytes should be transplanted as soon as possible, preferably within $24 \mathrm{hrs}$ of isolation, as the hepatic function deteriorates when kept at $4{ }^{\circ} \mathrm{C}$.

\section{Cell dose and route of administration}

Although $100 \%$ replacement of disease hepatocytes with healthy functional hepatocytes is ideal, the practical goal of replacement ratio will be $10-15 \%$, which may improve enzyme functions to the mild phenotype from the most of severe type congenital metabolic disorders [17-22]. It is assumed that $2 \times 108$ cells per kg of body weight may be the upper limit of hepatocytes that can be safely infused during transplantation. The currently proposed optimized dose is $30-100 \times 106$ cells/kg of body weight at an infusion rate of $5-10 \mathrm{ml} / \mathrm{kg}$ per hour, and a concentration of $1-10 \times 106$ cells $/ \mathrm{ml}$ [23]. To achieve the estimated number of cell transplantation, therefore, multiple infusions are necessary with certain interval periods [24].

Cell transplantation performed to target either liver or spleen. Although cell engraftment in the liver is physiological, spleen could be a good alternative destination in case the recipient's liver suffer from severe fibrosis (cirrhosis). The route of administration must be intraportal injection regardless directly inject into the intra hepatic portal vein, inferior mesenteric vein, umbilical vein, or via spleen. Systemically injected cells will be trapped in the lung and may cause the pulmonary thromboembolism. On the other hand, cells injected into portal vein do not pass through the liver [25]. Although the mechanism of cell integration in the recipient's hepatic lobule structure is not well studied, it is speculated that the intraportal infusion causes cell embolism at the intra hepatic portal capillary and increase the portal pressure. The portal hypertension and mechanical expansion stimulate intercellular signaling exchange between the non parenchymal cells which increase the vascular permeability [26,27].

\section{Recipient Liver Preconditioning Treatments}

Preconditioning treatments are common strategies used in preclinical studies to enhance engraftment and proliferation of donor cells [28]. The aims of the preconditioning treatments can be classified into four categories:

(1) Decrease recipient's immune reaction.

(2) Disrupt the native liver structure.

(3) Stimulate liver regeneration signalings and

(4) Supress the native hepatocyte proliferation.

The most common treatment is a partial hepatectomy combined with radiation or drugs, such as retro sine $[29,30]$. Although many of these strategies are not clinically acceptable, Fox [10] demonstrated a significant increase of cell engraftment with partial radiation in clinical hepatocyte transplantation [31]. Irradiation approach may serve all above four aims [32,33].

(1) The irradiation inhibits the phagocytic activity of Kupffer cells.

(2) Transiently disrupt the sinusoidal endothelial barrier.

(3) Induce apoptosis of native hepatocytes to stimulate liver regeneration and

(4) Inhibit native hepatocyte proliferation.

In addition, these effects can be controlled by optimizing the radiation dose. A total dose of $10 \mathrm{~Gy}$ for patients greater than 3 years of age, and 5Gy for patients less than that age was used in the clinical trial [31]. The donor cells injected into the portal vein were guided to the irradiated right lobe by the left branch occlusion. One of the advantages of hepatocyte transplantation is the native liver serves as a back-up to the therapy. Unlike OLT, 
the patient's condition only returns to the pre-transplantation state in case of cellular graft failure. A major concern of this preconditioning treatment is losing this advantage. The eligible recipients must be evaluated carefully.

\section{Limitations/Obstacles and Future direction}

There are several obstacles to provide this promising therapy to the patients as an option of standard therapies. Shortage of donor organs limits the availability of livers for hepatocyte isolation. In an endeavour to increase the opportunity to obtain primary human hepatocyte, the researchers extended the donor criteria to advanced -age donors and non-heart-beating donors. Fetal hepatocytes or immortalized hepatocytes were also considered as alternative cells [34]. However, none of them could resolve the problem. Recent advancements in stem cell research have demonstrated that hepatocyte -like cells can be derived from human stem cells.

Pluripotent stem cells such as embryonic stem cells (ESCs) and induced pluripotent stem cells (iPSCs) possess tremendous differentiation potentials, however, the developmental capability is a double-edged sword, associated with the risk of tumorigenicity [35]. It is almost impossible to guaranty the safety of injecting over two billion ESC or iPSC-derived hepatocytes with current technology. Other stem cells such as mesenchymal stem cells also proposed that they possess the hepatic differentiation capability. However, efficiency is still open to debate. One of the placental stem cells, human amnion epithelial cells (hAEC) has been getting attention as an alternative for hepatocyte transplantation $[36,37]$. hAECs possess multi- lineage differentiation potential including the ability to differentiate towards the hepatic lineage, which allows them to express the desired enzymatic functions [38].

Unlike other components of the placenta, the human amniotic epithelium is derived from pluripotent epiblasts [39-41]. Studies showed that the embryonic stem cell surface markers TRA1-60, TRA1-81, SSEA3, and SSEA4 are positive on most of the fetal amniotic epithelium and some of these stem cell marker positive cells are retained in term placental amniotic epithelium [40]. Primary hAECs respond to exogenous stimuli in vitro and can be induced towards specific differentiation. These morphological and transcriptional profile changes demonstrate the developmental plasticity of the hAECs. Under appropriate culture conditions, hAECs exhibit the capability of differentiating into endoderm lineage tissues including hepatocytes in vitro and in vivo.

Transcriptional analysis of hAECs transplanted SCID/ Beige mouse livers indicate that transplanted hAECs terminally differentiated into mature hepatocytes in mouse liver and expressed functional marker genes including cytochrome P450 genes at equivalent levels to human primary hepatocytes [42]. Several preclinical studies have demonstrated that the hAECderived hepatic cells acquire the desired enzyme function for the treatment of congenital metabolic disorders using disease model animals $[43,44]$. Other preclinical studies also demonstrated significant therapeutic properties of hAEC for cirrhosis [45].

Importantly, upon transplantation into the livers of mice, undifferentiated hAECs have been shown to engraft, display hepatocyte-like morphology, and express various hepatic enzymes without tumorigenicity. The lack of direct monitoring/ tracking technology after cell transplantation is another obstacle that prevents to make the cell therapy as one of the standard therapies [46]. The biochemical elevations of serum concentrations of aspartate transaminase (AST) and alanine transaminase (ALT) are the markers of liver rejection post OLT, as well as the histological signature of inflammatory cell infiltration in the graft. However, relatively less number of donor cells in case of hepatocyte transplantation limit to determine cell rejection with these assays.

Molecular biological approaches such as detecting Y chromosome sequences with qRT-PCR may be able to demonstrate the presence of donor cells, however, it will not indicate the cell viability. If the target enzyme function is restored or improved, that could be an indirect evidence of cell engraftment. However, these parameters may not be sensitive enough to control immune suppression in a practical manner. Development of novel methods to label cells will be required with a detection/tracking technology with single cell level high resolution. Novel biomarkers that correspond to the rejection will be helpful to optimize the immune suppression regimen $[47,48]$. It is critical to monitor the status of transplanted cells in order to optimize and design immune suppression regimen for each patient [49].

Currently similar immune suppression regimen used for OLT or islet transplantation is used for hepatocyte transplantation however, it could be reduced because of the immune privileged nature of the hepatocytes [50]. In summary, clinical hepatocyte transplantation studies have clearly demonstrated that this therapy is a suitable treatment for patients with CMDs. However, there are some obstacles to provide this promising therapy to the patients as an option of standard therapies. The obstacles are the insufficient supply of donor cells, the lack of direct monitoring/tracking technology after cell transplantation, which subsequently causes the difficulty to optimize immune suppression protocols. Further studies on stem cell-derived hepatic cells and finding novel biomarkers are required to translate the hepatocyte transplantation into clinic.

\section{Acknowledgement}

This work was supported by CIRM grant TR3-05488 (TM).

\section{Disclosure Statement}

The author owns stock in Noveome Biotherapeutics, Inc. The author has received no payment for the preparation of this manuscript and state no other financial and non-financial conflict of interests. 


\section{References}

1. Dhawan A, Puppi J, Hughes RD, Mitry RR (2010) Human hepatocyte transplantation: current experience and future challenges. Nat Rev Gastroenterol Hepatol 7(5): 288-298.

2. Hansel MC, Gramignoli R, Skvorak KJ, Dorko K, Marongiu F, et al. (2014) The history and use of human hepatocytes for the treatment of liver diseases: the first 100 patients. Curr Protoc Toxicol 62:14.12.1-14.12. $1-23$.

3. Matas AJ, Sutherland DE, Steffes MW, Mauer SM, Sowe A, et al. (1976) Hepatocellular transplantation for metabolic deficiencies: decrease of plasms bilirubin in Gunn rats. Science 192(4242): 892-894.

4. SK, MS, KK, HE, MM (1987) Intrasplenic hepatocyte transplantation in mammals. Transpl Proc 19: 992-994.

5. Mito M, Kusano M (1993) Hepatocyte transplantation in man. Cell Transplant 2(1): 65-74.

6. Strom SC, Bruzzone P, Cai H, Ellis E, Lehmann T, et al. (2006) Hepatocyte transplantation: Clinical experience and potential for future use. Cell Transplant 15(1): 105-110.

7. Ito M, Nagata H, Miyakawa S, Fox IJ (2009) Review of hepatocyte transplantation. J Hepatobiliary Pancreat Surg 16: 97-100.

8. Ohashi K, Park F, Kay MA (2001) Hepatocyte transplantation: clinical and experimental application. J Mol Med (Berl) 79(11): 617-630.

9. Gramignoli R, Vosough M, Kannisto K, Srinivasan RC, Strom SC (2015) Clinical hepatocyte transplantation: Practical limits and possible solutions. Eur Surg Res 54(3-4): 162-177.

10. Fox IJ, Chowdhury JR, Kaufman SS, Goertzen TC, Chowdhury NR, et al. (1998) Treatment of the Crigler-Najjar syndrome type I with hepatocyte transplantation. N Engl J Med 338(20): 1422-1426.

11. Gramignoli R, Tahan V, Dorko K, Skvorak KJ, Hansel MC, et al. (2013) New potential cell source for hepatocyte transplantation: Discarded livers from metabolic disease liver transplants. Stem Cell Res 11(1): 563-573.

12. Azoulay D, Samuel D, Castaing D, Adam R, Adams D, et al. (1999) Domino liver transplants for metabolic disorders: Experience with familial amyloidotic polyneuropathy. J Am Coll Surg 189(6): 584-593.

13. Hughes RD, Mitry RR, Dhawan A, Lehec SC, Girlanda R, et al. (2006) Isolation of hepatocytes from livers from non-heart-beating donors for cell transplantation. Liver Transplant 12(5): 713-717.

14. Puppi J, Strom SC, Hughes RD, Bansal S, Castell JV, et al. (2012) Improving the techniques for human hepatocyte transplantation: Report from a consensus meeting in London. Cell Transplant 21(1): 1-10.

15. Strom SC, Jirtle RL, Jones RS, Novicki DL, Rosenberg MR, et al. (1982) Isolation, culture, and transplantation of human hepatocytes. J Natl Cancer Inst 68(5): 771-778.

16. Bhogal RH, Hodson J, Bartlett DC, Weston CJ, Curbishley SM, et al (2011). Isolation of primary human hepatocytes from normal and diseased liver tissue: A one hundred liver experience. PLoS One 6(3): e18222.

17. Fisher RA, Strom SC (2006) Human hepatocyte transplantation: Worldwide results. Transplantation 82(4): 441-449.

18. Meyburg J, Das AM, Hoerster F, Lindner M, Kriegbaum H, et al (2009) One liver for four children: first clinical series of liver cell transplantation for severe neonatal urea cycle defects. Transplantation 87(5): 636-641.

19. Sokal EM, Smets F, Bourgois A, Van Maldergem L, Buts JPP, et al. (2003) Hepatocyte transplantation in a 4-year-old girl with peroxisomal biogenesis disease: technique, safety, and metabolic follow-up. Transplantation 76(4): 735-738
20. Muraca M, Gerunda G, Neri D, Vilei M, Granato A, et al. (2002) Hepatocyte transplantation as a treatment for glycogen storage disease type 1a. Lancet 359(9303): 317-318.

21. Strom SC, Chowdhury JR, Fox IJ (1999) Hepatocyte transplantation for the treatment of human disease. Semin Liver Dis 19(1): 39-48.

22. Dhawan A, Mitry RR, Hughes RD, Lehec S, Terry C, et al. (2004) Hepatocyte transplantation for inherited factor VII deficiency. Transplantation 78(12): 1812-1814.

23. Fisher RA, Bu D, Thompson M, Wolfe L, Ritter JK (2004) Optimization of conditions for clinical human hepatocyte infusion. Cell Transplant 13(6): 677-689.

24. Darwish AA, Sokal E, Stephenne X, Najimi M, de Ville de Goyet J, et al. (2004) Permanent access to the portal system for cellular transplantation using an implantable port device. Liver Transplant 10(9): 1213-1215.

25. Bohnen NI, Charron M, Reyes J, Rubinstein W, Strom SC, et al. (2000) Use of indium-111-labeled hepatocytes to determine the biodistribution of transplanted hepatocytes through portal vein infusion. Clin Nucl Med 25(6): 447-450.

26. Gupta S, Rajvanshi P, Sokhi R, Slehria S, Yam A, et al. (1999) Entry and integration of transplanted hepatocytes in rat liver plates occur by disruption of hepatic sinusoidal endothelium. Hepatology 29(2): 509519.

27. Gupta S, Rajvanshi P, Lee CD (1995) Integration of transplanted hepatocytes into host liver plates demonstrated with dipeptidyl peptidase IV-deficient rats. Proc Natl Acad Sci USA 92(13): 5860-5864.

28. Slehria S, Rajvanshi P, Ito Y, Sokhi RP, Bhargava KK, et al. (2002) Hepatic sinusoidal vasodilators improve transplanted cell engraftment and ameliorate microcirculatory perturbations in the liver. Hepatology 35(6): 1320-1328.

29. Laconi S, Curreli F, Diana S, Pasciu D, De Filippo G, et al. (1999) Liver regeneration in response to partial hepatectomy in rats treated with retrorsine: A kinetic study. J Hepatol 31(6): 1069-1074.

30. Laconi E, Oren R, Mukhopadhyay DK, Hurston E, Laconi S, et al. (1998) Long-term, near-total liver replacement by transplantation of isolated hepatocytes in rats treated with retrorsine. Am J Pathol 153(1): 319329.

31. Soltys KA, Setoyama K, Tafaleng EN, Soto Gutiérrez A, Fong J, et al. (2017) Host conditioning and rejection monitoring in hepatocyte transplantation in humans. J Hepatol 66(5): 987-1000.

32. Guha C, Sharma A, Gupta S, Roy Chowdhury N, Tanaka KE, et al. (1999) Amelioration of radiation-induced liver damage in partially hepatectomized rats by hepatocyte transplantation. Cancer Res 59(23): 5871-5874.

33. Yamanouchi K, Zhou H, Roy Chowdhury N, Macaluso F, Liu L, et al. (2009) Hepatic irradiation augments engraftment of donor cells following hepatocyte transplantation. Hepatology 49(1): 258-267.

34. Tolosa L, Pareja Ibars E, Teresa Donato M, Cortés M, López S, et al. (2014) Neonatal livers: A source for the isolation of good-performing hepatocytes for cell transplantation. Cell Transplant 23(10): 12291242.

35. Miki T (2011) Hepatic differentiation of human embryonic and induced pluripotent stem cells for regenerative medicine. In: Kallos PMS (Eds.), Embryonic Stem Cells Differ. Pluripotent In Tech, pp. 303-320.

36. Strom SC, Skvorak K, Gramignoli R, Marongiu F, Miki T (2013) Translation of amnion stem cells to the clinic. Stem Cells Dev 22(1): 96-102.

37. Miki T, Grubbs B (2014) Therapeutic potential of placenta-derived stem cells for liver diseases: Current status and perspectives. J Obstet Gynaecol Res 40(2): 360-368. 
38. Miki T, Lehmann T, Cai H, Stolz DB, Strom SC (2005) Stem cell characteristics of amniotic epithelial cells. Stem Cells 23(10): 15491559.

39. Miki T (2011) Amnion-derived stem cells: in quest of clinical applications. Stem Cell Res Ther 2(3): 25.

40. Izumi M, Pazin BJ, Minervini CF, Gerlach J, Ross MA, et al. (2009) Quantitative comparison of stem cell marker-positive cells in fetal and term human amnion. J Reprod Immunol 81(1): 39-43.

41. Miki T, Strom SC (2006) Amnion-derived pluripotent/multipotent stem cells. Stem Cell Rev 2(2): 133-142.

42. Marongiu F, Gramignoli R, Dorko K, Miki T, Ranade AR, et al. (2011) Hepatic differentiation of amniotic epithelial cells. Hepatology 53(5): 1719-1729.

43. Skvorak KJ, Dorko K, Marongiu F, Tahan V, Hansel MC, et al. (2013) Improved amino acid, bioenergetic metabolite and neurotransmitter profiles following human amnion epithelial cell transplant in intermediate maple syrup urine disease mice. Mol Genet Metab 109(2): 132-138.

44. Rodriguez NS, Yanuaria L, Parducho KMR, Garcia IM, Varghese BA, et al. (2017) Liver-directed human amniotic epithelial cell transplantation improves systemic disease phenotype in hurler syndrome mouse model. Stem Cells Transl Med 6(7): 1583-1594.
45. Lin JS, Zhou L, Sagayaraj A, Jumat NHB, Choolani M, et al. (2015) Hepatic differentiation of human amniotic epithelial cells and in vivo therapeutic effect on animal model of cirrhosis. J Gastroenterol Hepatol 30(11): 1673-1682.

46. Cen P, Chen J, Hu C, Fan L, Wang J, et al. (2016) Noninvasive in-vivo tracing and imaging of transplanted stem cells for liver regeneration. Stem Cell Res Ther 7(1): 143.

47. Luo X, Miller SD, Shea LD (2016) Immune Tolerance for autoimmune disease and cell transplantation. Annu Rev Biomed Eng 18:181-205.

48. Jorns C, Nowak G, Nemeth A, Zemack H, Mörk LM, et al. (2015) De Novo donor-specific HLA antibody formation in two Patients with criglernajjar syndrome type I following human hepatocyte transplantation with partial hepatectomy preconditioning. Am J Transplant 16(3): 1021-1030.

49. Mukherjee S, Mukherjee U (2009) A Comprehensive review of immunosuppression used for liver transplantation. J Transplant 2009: 701464 .

50. Bogdanos DP, Gao B, Gershwin ME (2013) Liver immunology. Compr Physiol 3(2): 567-598.

\section{Your next submission with JuniperPublishers will reach you the below assets}

- Quality Editorial service

- Swift Peer Review

- Reprints availability

- E-prints Service

- Manuscript Podcast for convenient understanding

- Global attainment for your research

- Manuscript accessibility in different formats

( Pdf, E-pub, Full Text, audio)

- Unceasing customer service

Track the below URL for one-step submission https://juniperpublishers.com/online-submission.php 